\title{
Spectral reflectance response to nitrogen fertilization in field grown corn
}

\author{
Chuanqi Xie ${ }^{1}$, Ce Yang ${ }^{1 *}$, Alexander Hummel J r ${ }^{2}$, Gregg A J ohnson ${ }^{3,4}$, Forrest T Izuno ${ }^{1,4}$ \\ (1. Department of Bioproducts and Biosystems Engineering, University of Minnesota, Saint Paul, MN 55108, United States; \\ 2. Farm Nutrients Inc., 4949 Hwy 71, Rembrandt, IA 50576, United States; \\ 3. Department of Agronomy and Plant Genetics, University of Minnesota, Saint Paul, MN 55108, United States; \\ 4. Southern Research and Outreach Center, University of Minnesota, Waseca, MN 56093, United States)
}

\begin{abstract}
This study was carried out to analyze the spectral reflectance response of different nitrogen levels for corn crops. Four different nitrogen treatments of $0 \%, 80 \%, 100 \%$ and 120\% BMP (best management practice) were studied. Principal component analysis-loading (PCA-loading) was used to identify the effective wavelengths. Partial least squares (PLS) and multiple linear regression (MLR) models were built to predict different nitrogen values. Vegetation indices (VIs) were calculated and then used to build more prediction models. Both full and selected wavelengths-based models showed similar prediction trends. The overall PLS model obtained the coefficient of determination $\left(R^{2}\right)$ of 0.6535 with a root mean square error (RMSE) of 0.2681 in the prediction set. The selected wavelengths for overall MLR model obtained the $R^{2}$ of 0.6735 and RMSE of 0.3457 in the prediction set. The results showed that the wavelengths in visible and near infrared region (350$1000 \mathrm{~nm}$ ) performed better than the two either spectral regions (1001-1350/1425-1800 nm and 2000-2400 nm). For each data set, the wavelengths around $555 \mathrm{~nm}$ and $730 \mathrm{~nm}$ were identified to be the most important to predict nitrogen rates. The vogelmann red edge index 2 (VOG 2) performed the best among all VIs. It demonstrated that spectral reflectance has the potential to be used for analyzing nitrogen response in corn.
\end{abstract}

Keywords: spectrum, effective wavelengths, principal component analysis-loading (PCA-loading), prediction, vegetation indices (VIs), corn

DOI: $10.25165 /$ j.ijabe.20181104.2960

Citation: Xie C Q, Yang C, Hummel Jr A, Johnson G A, Izuno F T. Spectral reflectance response to nitrogen fertilization in field grown corn. Int J Agric \& Biol Eng, 2018; 11(4): 118-126.

\section{Introduction}

The United States Department of Agriculture (USDA) reports that approximately 8.1 million acres of corn were planted in Minnesota in 2015. These yields resulted in 1.43 billion bushels of corn grain, 9.68 million tons of corn silage, and 4.8 US billion dollars $^{[1]}$. Nitrogen is an essential nutrient for corn production but is oftentimes limited even in the highly productive soils of Minnesota $^{[2]}$. Consequently, the application of nitrogen is critical for optimizing crop yield and quality ${ }^{[3]}$. Applying too much nitrogen leads to production inefficiencies while applying too little can result in significant yield loss. Regardlessly, there is a potential for substantial financial loss. The balance between applying suitable amount of nitrogen for optimal production while minimizing over-application to avoid associated potential environment pollution is key to a long and short-term sustainability of corn production ${ }^{[4]}$. It is important to understand the nitrogen status in corn crops at different growth stages to improve nitrogen

\section{Received date: 2016-11-26 Accepted date: 2018-05-06}

Biographies: Chuanqi Xie, PhD, Post-Doctoral Associate, research interests: hyperspectral imaging, remote sensing and unmanned aerial vehicle, Email: cqxie@umn.edu; Alexander Hummel Jr, Graduate Student, research interests: spectral features of corn crops, Email: humm@umn.edu; Gregg A Johnson, $\mathrm{PhD}$, Associate Professor, research interests: biomass production and alternative cropping systems, Email: johns510@umn.edu; Forrest T Izuno, PhD, Professor, research interests: cropping systems, agricultural water quality and quantity, Email: izuno001@umn.edu.

*Corresponding author: Ce Yang, PhD, Assistant Professor, research interest: apple orchard yield and ripeness mapping, early fruit maturity detection using hyperspectral imaging, and unmanned aerial vehicle. Mailing Address: 1390 Eckles Ave, Saint Paul, MN 55108, USA. Tel: +1 612-626-6419, Fax: +1 612-626-6419, Email: ceyang@umn.edu. application efficiency, increase financial benefits and contribute to a more sustainable agriculture practice ${ }^{[5-7]}$. Currently, most farmers apply a uniform rate of nitrogen fertilizer in the fall prior to planting corn. During the period from early fall to late spring, there is significant risk of surface and subsurface nitrogen loss, especially in spring due to excess soil moisture from snow melt and rainfall. To reduce nitrogen runoff, variable rate of nitrogen application is recommended both in time and space to replace single uniform nitrogen applications in the fall. Nitrogen deficiencies in corn vary spatially and temporally in agricultural fields, leading to significant yield loss if not treated in time. Early detection of these deficiencies (mid to late June) while the crop is actively growing can be followed by a variable rate nitrogen fertilizer application to prevent yield loss and avoid adverse environmental effects. However, early detection of nitrogen deficiencies (detection of nitrogen rates) is challenging because of the limitations of human labor.

The traditional single rate nitrogen application prior to corn planting (most often based on arbitrary yield goals) may not meet the needs of the crop during the growing season, ultimately resulting in inefficiencies and negative environmental consequences $^{[4,8,9]}$. Obtaining in-season information on plant nitrogen status is essential to improve production efficiency, avoid nitrogen leaching, and increase economic gains ${ }^{[10]}$. Remote sensing techniques take advantage of the optical properties of the corn plant to determine corn nitrogen status. Using this information will help to make better decisions ${ }^{[11]}$. Previous studies have focused on nitrogen status using spectral or hyperspectral techniques. Vigneau et al. ${ }^{[3]}$ estimated the nitrogen content in wheats based on the reflectance information in the spectral range of 400-1000 nm. The researchers used two 
different sets of data and achieved a good prediction result $\left(R^{2}=0.875\right)$. Min et al. ${ }^{[12]}$ predicted the nitrogen content in citrus trees using the spectral reflectance in 400-2500 nm. Six important wavelengths (448 nm, $669 \mathrm{~nm}, 719 \mathrm{~nm}, 1377 \mathrm{~nm}, 1773 \mathrm{~nm}$ and $2231 \mathrm{~nm}$ ) were identified from the whole wavebands. Based on the selected wavebands, the $R^{2}$ for the validation set of stepwise multiple linear regression was 0.839. Albayrak et al. ${ }^{[13]}$ detected nitrogen content in Sainfoin Pasture using a portable spectroradiometer covering the wavelengths of $325-1150 \mathrm{~nm}$. The prediction results $\left(R^{2}\right)$ of nitrogen were between 0.85 and 0.87 for stepwise regression. In this study, we focus on four different nitrogen levels $(0 \%, 80 \%, 100 \%$ and $120 \%$ of the best management practice, BMP) prediction using spectral reflectance. The spectral reflectance data were collected at different dates in order to produce robust and reliable results.

According to Minnesota Department of Agriculture, BMP for nitrogen was first described in 1980s-1990s. It is defined as economically sound, voluntary practices that are capable of minimizing nitrate-nitrogen $\left(\mathrm{NO}_{3}^{-}-\mathrm{N}\right)$ contamination of surface and ground water ${ }^{[14]}$. In this study, spectral reflectance data of corn crops before tasseling and after tasseling (reproductive stage) were utilized to evaluate different nitrogen response. This approach allows the application of nitrogen fertilizer based on a non-destructive detection method, leading to more efficient nitrogen use and less contamination of surface and ground water.

The specific objectives were to: (1) find the relationship between four different nitrogen levels and spectral reflectance data;
(2) select useful wavelengths and vegetation indices (VIs); (3) achieve the linear equations for nitrogen values; and (4) compare the performance of different prediction models.

\section{Materials and methods}

\subsection{Flowchart}

The main steps of this work were shown in Figure 1. First, spectral reflectance was acquired from corn rows within each of the four nitrogen fertilizer levels on six separate dates. Spectrum noise at the wavelengths intervals of 1350-1425 nm, 1800-2000 nm and 2400-2500 nm were deleted. Partial least squares (PLS) models were built based on the remaining wavelengths. To identify the wavelengths that are the most important for prediction, principal component analysis-loading (PCA-loading) was carried out to select significant wavelengths in this study. Using the selected wavelengths, multiple linear regression (MLR) models were established. Each model was evaluated using the values of coefficient of determination in calibration $\left(R_{c}{ }^{2}\right)$ and prediction $\left(R_{p}{ }^{2}\right)$ as well as root mean square error in calibration (RMSEC) and prediction (RMSEP). Based on the regression coefficient values, the linear prediction equations for the relationship between spectral reflectance data and nitrogen level values can be acquired. The performance of each selected wavelength was compared using calculated $t$-values. Finally, the most important wavelengths were used for detecting different nitrogen level values. Several VIs were extracted and the performance of each VI was calculated using Pearson's correlation and analysis of variance (ANOVA).

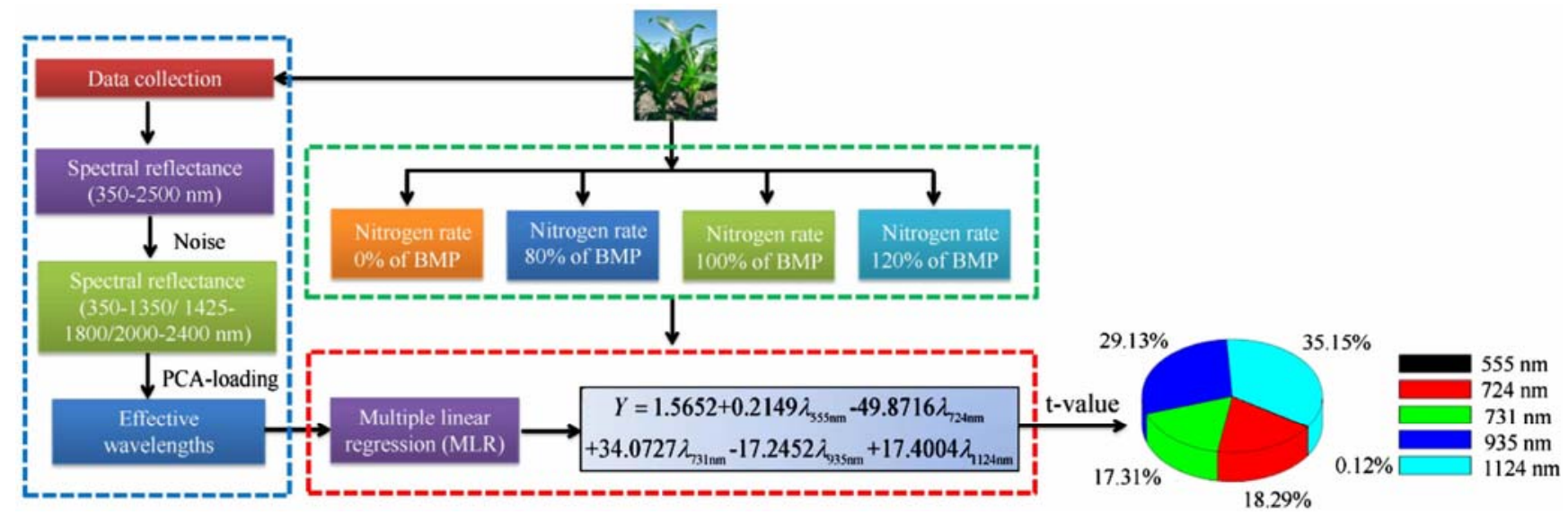

Figure 1 Flowchart of this study

\subsection{Experiment design}

Corn (DeKalb DKC 53-56RIB) were planted on April 28, 2015 at a seeding rate of 69188 seeds $/ \mathrm{hm}^{2}$ in $76 \mathrm{~cm}$ rows in trial plots located at the Southern Research and Outreach Center in Waseca, Minnesota. The experiment design is a randomized complete block with four replications. Main plots are $24.4 \mathrm{~m}^{2}$ and composed of individual crops within a given cropping system. Data were collected in four $6.1 \mathrm{~m}^{2}$ sub-plots within each main plot. The recommended nitrogen rate was $72.8 \mathrm{~kg} / \mathrm{hm}^{2}$ of urea for corn after soybean either with or without a cereal rye cover crop. For corn following corn, the recommended nitrogen rate was $140 \mathrm{~kg} / \mathrm{hm}^{2}$. Sub-plots within each plot contained four nitrogen levels that included $0 \%, 80 \%, 100 \%$, and $120 \%$ of the recommended nitrogen rate according to University of Minnesota nitrogen BMP guidelines for the region. All nitrogen was applied on April 18, 2015.

\subsection{Analytical Spectral Devices (ASD) and software}

The spectral reflectance data were collected using the FieldSpec 4 Hi-Res: high resolution spectroradiometer (Analytical
Spectral Device Inc., Boulder, CO, USA). The spectral range is from $350 \mathrm{~nm}$ to $2500 \mathrm{~nm}$ with a spectral resolution of $3 \mathrm{~nm}$ at $700 \mathrm{~nm}$ and $8 \mathrm{~nm}$ at 1400/2100 nm. The sampling interval is $1.4 \mathrm{~nm}$ for the spectral region of $350-1000 \mathrm{~nm}$ and $1.1 \mathrm{~nm}$ for the spectral region of 1001-2500 $\mathrm{nm}$. The spectrometer has three separate holographic diffraction gratings with three independent detectors. Each detector is covered with the appropriate order separation filters to eliminate the second and higher order light.

The visible/near infrared (Vis/NIR) detector $(350-1000 \mathrm{~nm})$ is a 512 element silicon array, the short-wave infrared spectroscopy (SWIR) 1 detector (1001-1800 nm) has a graded index InGaAs photodiode exhibiting a two-stage TE cooler, and the SWIR 2 detector (1801-2500 nm) contains a graded index InGaAs photodiode also exhibiting a two-stage TE cooler. IBM SPSS Statistics V22 (IBM, Armonk, NY, USA) and Unscrambler X10.1 (CAMO Process As, Oslo, Norway) were used for analyzing the data, identifying useful wavelengths and building regression models. 


\subsection{Data collection}

Spectral reflectance data were collected on six dates $(6 / 29$, $7 / 13,7 / 29,8 / 11,8 / 25$ and 9/14) during the 2015 growing season. This study was a part of the Long-Term Agricultural Research Network (LTARN) trial at the University of Minnesota's Southern Research and Outreach Center (Waseca, Minnesota, USA). Data acquisition occurred on cloudless days between the times of $1000 \mathrm{hr}$ and $1400 \mathrm{hr}$ using the FieldSpec 4 Hi-Res spectroradiometer. The instrument was warmed up for twenty minutes to allow internal detectors to reach their equivalent temperatures. The fiber optic sensor of the spectroradiometer with a $25^{\circ}$ field of view was placed in a nadir position above the corn canopy. Before tasseling (6/29/2015 and 7/13/2015), the sensor was 1 meter above the center of the crop canopy. As the crop grew, a jumper cable was needed to reach the higher position above the corn rows. The maximum height achievable after tasseling in this configuration was 0.75 meters above the flag leaf of the crop canopy. The scan average was increased by $20 \%$ (from 10 to 12) to help mitigate the decrease in signal to noise ratio of the longer fiber optic. Optimization and white reference were taken before each plot to account for changes in solar angle. Ten measurements were taken by walking down the fourth row of each plot at a working pace of $1 \mathrm{~m} / \mathrm{s}$. Row ends were excluded from measurements to eliminate end row effects. After spectrum collection, all data were divided into calibration and prediction sets with a ratio of 2:1. The samples in the calibration set were used for establishing the model, while those in the prediction set were applied to validate the model.

\subsection{Prediction models and evaluation}

In this study, PLS model was established to predict different levels of nitrogen within the crops. This method has been used in previous studies ${ }^{[15-18]}$ and is effective when applied to predicting collinear variables. A set of orthogonal factors which contain most of the significant information can be extracted to produce the prediction results ${ }^{[19]}$. The procedure was finished by removing one sample and building a PLS model with the remaining samples. The same calculation was repeated for each sample to achieve acceptable results. MLR is another effective regression method that combines a set of $X$ variables in linear combinations. It correlates with best fit to the corresponding $Y$ variables. This model can be written as $Y=b_{0}+b_{1} X_{1}+\ldots b_{n} X_{n}+e$, in which the response values are approximated by a linear combination of values for the predictors and $b_{0}, b_{1} \ldots b_{n}$ are regression coefficients ${ }^{[20]}$.The model performance was evaluated by the values of $R_{c}{ }^{2}, R_{p}{ }^{2}$, RMSEC and RMSEP. High values of $R_{c}{ }^{2}$ and $R_{p}{ }^{2}$, low values of $R M S E C$ and RMSEP and a small difference between $R_{c}{ }^{2}$ and $R_{p}{ }^{2}$ indicate that the performance is excellent ${ }^{[21]}$.

\subsection{Wavelengths selection}

The original full wavelengths are characterized with redundant information. This information contains too many variables and cannot be used for real applications. Effective wavelengths selection is a significant step in spectral analysis. Usually, the selected wavelengths can simplify the model and produce equivalent or improved models compared with full spectral wavelengths ${ }^{[22,23]}$. PCA-loading was carried out to select the most useful wavelengths in this study. The aim of this method was to identify a small subset of spectral features to replace the whole wavelengths. In each PCA-loading plot, the highest positive and lowest negative peaks represent that the wavelengths contain the most useful information. This is an indication that these wavelengths could produce good performance for evaluating nitrogen levels in corn ${ }^{[24]}$. Each plot shows the relationship between the $Y$-variables and corresponding $X$-variables.

\subsection{Vegetation indices}

In this study, a total of 12 VIs were used to evaluate nitrogen levels. VIs can be obtained from the surface spectral reflectance at two or more wavelengths using mathematical calculations. The errors caused by atmospheric effects, solar illumination, soil background and sensor viewing geometry can usually be reduced by $\mathrm{VIs}^{[25]}$. The description for each VI can be seen in Table 1 . $R_{\mathrm{i}}$ is the spectral reflectance value at wavelength $i$. For example, $R_{\mathrm{NIR}}$ stands for the spectral reflectance value at $800 \mathrm{~nm}, R_{\mathrm{Red}}$ means the spectral reflectance value at $680 \mathrm{~nm}$, and $R_{\text {Blue }}$ is corresponding to the spectral reflectance value at $450 \mathrm{~nm}$.

Table 1 Description of the VIs ${ }^{[26]}$

\begin{tabular}{|c|c|}
\hline Vegetation indices & Description \\
\hline $\mathrm{NDVI}=\frac{R_{\mathrm{NIR}}-R_{\mathrm{Red}}}{R_{\mathrm{NIR}}+R_{\mathrm{Red}}}$ & $\begin{array}{l}\text { Represents green vegetation or } \\
\text { biomass with values closer to } 1 \\
\text { representing healthy plants. }\end{array}$ \\
\hline $\mathrm{SRI}=\frac{R_{\mathrm{NIR}}}{R_{\mathrm{Red}}}$ & Saturates in dense vegetation. \\
\hline $\mathrm{EVI}=2.5 \times\left(\frac{R_{\mathrm{NIR}}-R_{\mathrm{Red}}}{R_{\mathrm{NIR}}+6 \times R_{\mathrm{Red}}-7.5 \times R_{\mathrm{Blue}}+1}\right)$ & $\begin{array}{l}\text { Accounts for soil background and } \\
\text { atmospheric aerosol effects. }\end{array}$ \\
\hline $\mathrm{ARVI}=\frac{R_{\mathrm{NIR}}-\left(2 R_{\mathrm{Red}}-R_{\mathrm{Blue}}\right)}{R_{\mathrm{NIR}}+\left(2 R_{\mathrm{Red}}-R_{\mathrm{Blue}}\right)}$ & $\begin{array}{l}\text { Resistant to atmospheric factors. } \\
\text { The reflectance in blue can } \\
\text { correct the reflectance in red for } \\
\text { atmospheric scattering. }\end{array}$ \\
\hline SGI (Sum Green Index) & $\begin{array}{l}\text { Can be used to detect changes of } \\
\text { vegetation greenness. }\end{array}$ \\
\hline $\mathrm{NDVI}_{705}=\frac{R_{750}-R_{705}}{R_{750}+R_{705}}$ & $\begin{array}{l}\text { Modified NDVI using reflectance } \\
\text { along the red edge. }\end{array}$ \\
\hline $\mathrm{mSR}_{705}=\frac{R_{750}-R_{445}}{R_{705}+R_{445}}$ & $\begin{array}{l}\text { Modified SRI with correction of } \\
\text { leaf specular reflection. }\end{array}$ \\
\hline $\mathrm{mNDVI}_{705}=\frac{R_{750}-R_{705}}{R_{750}+R_{705}-2 R_{445}}$ & $\begin{array}{l}\text { Modified Red Edge NDVI which } \\
\text { can consider for scattered light. }\end{array}$ \\
\hline $\operatorname{VOG} 1=\frac{R_{740}}{R_{720}}$ & $\begin{array}{l}\text { Sensitive to the effects of } \\
\text { chlorophyll concentration, leaf } \\
\text { area and water content. }\end{array}$ \\
\hline VOG $2=\frac{R_{734}-R_{747}}{R_{715}+R_{726}}$ & $\begin{array}{l}\text { Sensitive to the effects of } \\
\text { chlorophyll concentration, leaf } \\
\text { area and water content. }\end{array}$ \\
\hline VOG $3=\frac{R_{734}-R_{747}}{R_{715}+R_{720}}$ & $\begin{array}{l}\text { Sensitive to the effects of } \\
\text { chlorophyll concentration, leaf } \\
\text { area and water content. }\end{array}$ \\
\hline $\mathrm{NDN} \mathrm{I}=\frac{\log \left(1 / R_{1510}\right)-\log \left(1 / R_{1680}\right)}{\log \left(1 / R_{1510}\right)+\log \left(1 / R_{1680}\right)}$ & $\begin{array}{l}\text { Measures the relative amounts of } \\
\text { nitrogen within vegetation } \\
\text { canopies. }\end{array}$ \\
\hline
\end{tabular}

\section{Results and discussion}

\subsection{Spectral features}

The spectral reflectance curves covering the whole wavelengths were shown in Figure 2a. Too much spectrum noise was detected at the wavelengths of 1350-1425 nm, 1800-2000 nm and $2400-2500 \mathrm{~nm}$ for the original spectral curves. To obtain more useful information and reduce redundant information, the wavelengths containing noise were abandoned. Because there are three different sensors with unique ranges for the entire spectral range $(350-1000 \mathrm{~nm}, 1001-1800 \mathrm{~nm}$ and $1801-2500 \mathrm{~nm})$, we narrowed the spectral ranges to $350-1350 \mathrm{~nm}, 1425-1800 \mathrm{~nm}$ and 2000-2400 nm for further analysis. Thus, 1778 spectral wavebands including band 1-1001, band 1076-1451 and band 1651-2051 were treated as $X$ variables. Different nitrogen values were treated as $Y$ variables. By establishing multiple regression models, we were able to predict nitrogen values. 
Figure $2 \mathrm{~b}$ shows the average spectral reflectance curves of different dates. The wavelength at $555 \mathrm{~nm}$ is the nitrogen absorption band which correlates to absorbed light by nitrogen within the crop tissue ${ }^{[27]}$. It shows that spectral reflectance values at $555 \mathrm{~nm}$ generally increased with time. The lowest spectral reflectance value at $555 \mathrm{~nm}$ occurred on 7/13/2015, indicating that nitrogen content in leaf tissue was the highest at this stage. The wavelengths at $970 \mathrm{~nm}$ and $1450 \mathrm{~nm}$ are water absorption bands or areas in which water absorbs incoming light ${ }^{[15,28]}$. The low spectral reflectance at wavelengths $400-700 \mathrm{~nm}$ is caused by strong absorption of photoactive pigments, such as chlorophylls, anthocyanins and carotenoids. The high reflectance from $700 \mathrm{~nm}$ to $1200 \mathrm{~nm}$ is due to multiple scattering of leaf cells. At 1200$1350 \mathrm{~nm}, 1425-1800 \mathrm{~nm}$ and 2000-2400 nm, the spectral reflectance decreased again due to the absorption of water and proteins ${ }^{[29]}$.

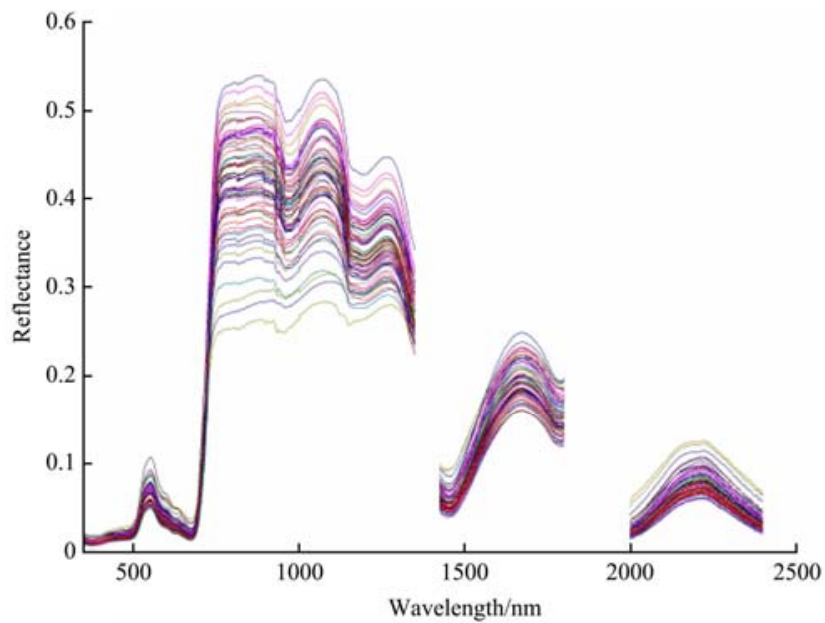

a. Spectral reflectance acquired on 6/29/2015

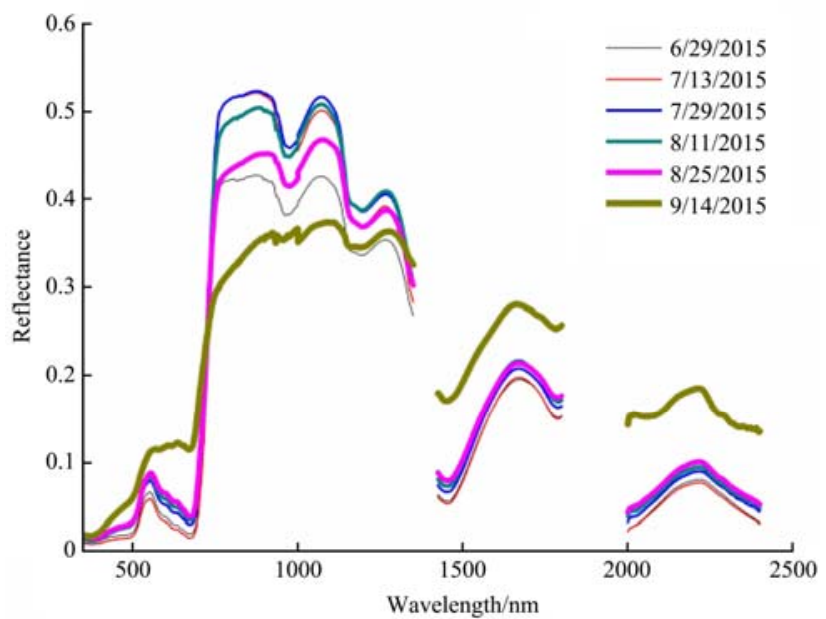

b. Average spectral reflectance acquired at different dates

Figure 2 Spectral reflectance and average spectral reflectance acquired without noise

\subsection{Prediction results}

PLS models were first established based on all spectral wavelengths. General prediction results were high except for the last data acquisition date (9/14/2015) (Table 2). This may be because the corn reached maturity on 9/14/2015 when nitrogen had been allocated to grain from leaf tissues. Consequently, the relationship between spectral reflectance data and nitrogen was not significant on this date. However, the data acquired on 6/29/2015, $7 / 29 / 2015$ and $8 / 11 / 2015$ obtained high $R_{p}{ }^{2}$ values of 0.7472 , 0.7447 and 0.7710 , and the overall data showed $R_{p}{ }^{2}$ of 0.6535 and
RMSEP of 0.2681 , indicating that PLS models were excellent for predicting the nitrogen level values.

Table 2 Prediction results of different PLS models for the combination of wavelengths at $350-1350 \mathrm{~nm}, 1425-1800 \mathrm{~nm}$ and 2000-2400 nm

\begin{tabular}{cccc}
\hline Date & Parameters & Calibration & Prediction \\
\hline \multirow{2}{*}{$6 / 29 / 2015$} & $R^{2}$ & 0.7778 & 0.7472 \\
& $R M S E$ & 0.2148 & 0.2290 \\
\hline \multirow{2}{*}{$7 / 13 / 2015$} & $R^{2}$ & 0.7404 & 0.6359 \\
& $R M S E$ & 0.2321 & 0.2749 \\
\hline \multirow{2}{*}{$7 / 29 / 2015$} & $R^{2}$ & 0.7667 & 0.7447 \\
& $R M S E$ & 0.2200 & 0.2302 \\
\hline \multirow{2}{*}{$8 / 11 / 2015$} & $R^{2}$ & 0.7200 & 0.7710 \\
& $R M S E$ & 0.2410 & 0.2180 \\
\hline \multirow{2}{*}{ 8/25/2015 } & $R^{2}$ & 0.7120 & 0.7180 \\
& $R M S E$ & 0.2452 & 0.2419 \\
\hline \multirow{2}{*}{ 9/14/2015 } & $R^{2}$ & 0.4889 & 0.2079 \\
& $R M S E$ & 0.3257 & 0.4054 \\
\hline \multirow{2}{*}{ Overall } & $R^{2}$ & 0.6642 & 0.6535 \\
& $R M S E$ & 0.2640 & 0.2681 \\
\hline
\end{tabular}

Since the spectrometer is configured to have three separate holographic diffraction gratings with three separate detectors (350-1000 nm, 1001-1800 nm and 1801-2500 nm), each spectral region was used to establish regression models. Considering noise covers the whole spectral wavelengths, the three spectral regions were divided into 350-1000 nm, 1001-1350/1425-1800 nm and 2000-2400 nm. The results for each region can be seen in Table 3, in which wavelengths $350-1000 \mathrm{~nm}$ performed the best among the three different spectral regions. This is because the spectrum information at wavebands $350-1000 \mathrm{~nm}$ is related to chlorophyll ${ }^{[29]}$, indicating that the sensitive wavelengths for nitrogen (chlorophyll) are located in this spectral range. The wavelengths 1001-1350/1425-1800 nm performed the second best for prediction, and 2000-2400 nm performed the worst. Thus, further study should be carried out using the spectral wavelength from $350 \mathrm{~nm}$ to $1000 \mathrm{~nm}$.

Table 3 Prediction results of PLS models at different wavelength regions

\begin{tabular}{|c|c|c|c|c|}
\hline Date & Wavelength/nm & Parameters & Calibration & Prediction \\
\hline \multirow{6}{*}{ 6/29/2015 } & \multirow{2}{*}{$350-1000$} & $R^{2}$ & 0.8176 & 0.7479 \\
\hline & & $R M S E$ & 0.1946 & 0.2287 \\
\hline & \multirow{2}{*}{$1001-1350 / 1425-1800$} & $R^{2}$ & 0.7974 & 0.5252 \\
\hline & & $R M S E$ & 0.2051 & 0.3139 \\
\hline & \multirow{2}{*}{$2000-2400$} & $R^{2}$ & 0.3584 & 0.1342 \\
\hline & & $R M S E$ & 0.3649 & 0.4751 \\
\hline \multirow{6}{*}{$7 / 13 / 2015$} & \multirow{2}{*}{$350-1000$} & $R^{2}$ & 0.7350 & 0.6164 \\
\hline & & RMSE & 0.2345 & 0.2821 \\
\hline & \multirow{2}{*}{$1001-1350 / 1425-1800$} & $R^{2}$ & 0.8703 & 0.3298 \\
\hline & & $R M S E$ & 0.1640 & 0.5020 \\
\hline & \multirow{2}{*}{$2000-2400$} & $R^{2}$ & 0.2840 & 0.0966 \\
\hline & & $R M S E$ & 0.3854 & 0.4330 \\
\hline \multirow{6}{*}{ 7/29/2015 } & \multirow{2}{*}{$350-1000$} & $R^{2}$ & 0.7526 & 0.7365 \\
\hline & & RMSE & 0.2266 & 0.2338 \\
\hline & \multirow{2}{*}{$1001-1350 / 1425-1800$} & $R^{2}$ & 0.8024 & 0.6137 \\
\hline & & RMSE & 0.2025 & 0.2831 \\
\hline & \multirow{2}{*}{$2000-2400$} & $R^{2}$ & 0.3794 & 0.0863 \\
\hline & & $R M S E$ & 0.3589 & 0.4354 \\
\hline
\end{tabular}




\begin{tabular}{|c|c|c|c|c|}
\hline Date & Wavelength/nm & Parameters & Calibration & Prediction \\
\hline \multirow{6}{*}{$8 / 11 / 2015$} & \multirow{2}{*}{$350-1000$} & $R^{2}$ & 0.7797 & 0.6930 \\
\hline & & $R M S E$ & 0.2138 & 0.2524 \\
\hline & \multirow{2}{*}{$1001-1350 / 1425-1800$} & $R^{2}$ & 0.8630 & 0.3476 \\
\hline & & RMSE & 0.1686 & 0.3679 \\
\hline & \multirow{2}{*}{$2000-2400$} & $R^{2}$ & 0.6658 & 0.0704 \\
\hline & & $R M S E$ & 0.2634 & 0.5136 \\
\hline \multirow{6}{*}{$8 / 25 / 2015$} & \multirow{2}{*}{$350-1000$} & $R^{2}$ & 0.6861 & 0.7091 \\
\hline & & RMSE & 0.2552 & 0.2457 \\
\hline & \multirow{2}{*}{$1001-1350 / 1425-1800$} & $R^{2}$ & 0.6574 & 0.6717 \\
\hline & & RMSE & 0.2666 & 0.2610 \\
\hline & \multirow{2}{*}{$2000-2400$} & $R^{2}$ & 0.0125 & 0.0017 \\
\hline & & $R M S E$ & 0.4527 & 0.4620 \\
\hline \multirow{6}{*}{$9 / 14 / 2015$} & \multirow{2}{*}{$350-1000$} & $R^{2}$ & 0.4612 & 0.2248 \\
\hline & & RMSE & 0.3344 & 0.4011 \\
\hline & \multirow{2}{*}{$1001-1350 / 1425-1800$} & $R^{2}$ & 0.5023 & 0.2037 \\
\hline & & $R M S E$ & 0.3214 & 0.4065 \\
\hline & \multirow{2}{*}{$2000-2400$} & $R^{2}$ & 0.0052 & 0.0131 \\
\hline & & RMSE & 0.4543 & 0.4525 \\
\hline \multirow{6}{*}{ Overall } & \multirow{2}{*}{$350-1000$} & $R^{2}$ & 0.6427 & 0.6498 \\
\hline & & $R M S E$ & 0.2723 & 0.2696 \\
\hline & \multirow{2}{*}{$1001-1350 / 1425-1800$} & $R^{2}$ & 0.4681 & 0.3598 \\
\hline & & RMSE & 0.3322 & 0.3645 \\
\hline & \multirow{2}{*}{$2000-2400$} & $R^{2}$ & 0.1440 & 0.0402 \\
\hline & & $R M S E$ & 0.4215 & 0.4728 \\
\hline
\end{tabular}
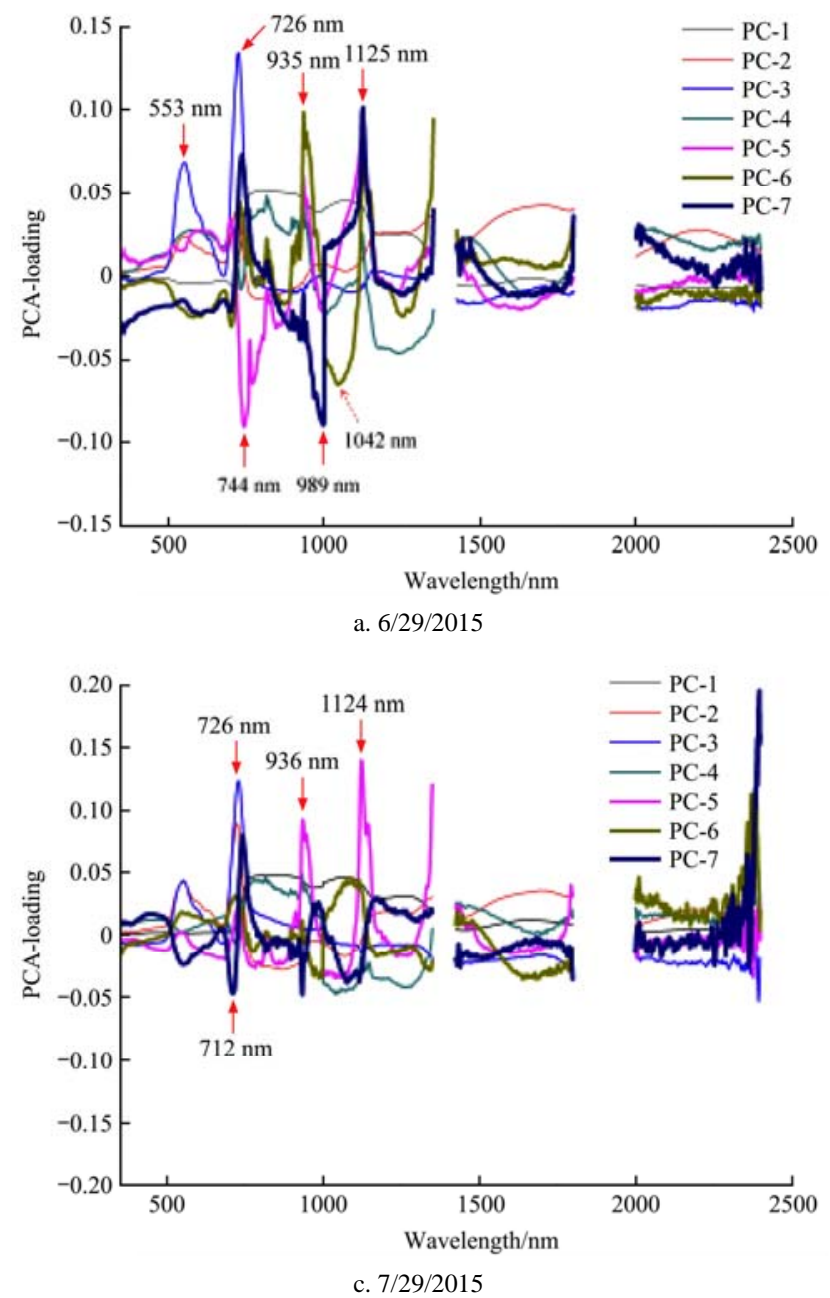

\subsection{Effective wavelengths selected by PCA-loading}

Larger absolute PCA-loading values indicate wavelengths at these points contain more effective information. Most of these values occurred at spectral peaks or valleys. For each set of data, the PCA-loading recommended the first seven principal components (PCs) (Figure 3). In Figure 3, the horizontal-axis is corresponding to the spectral wavelengths, and the vertical-axis is corresponding to the PCA-loading values. It can be found large absolute values were identified as the useful wavelengths. The number of selected wavelengths for each data set only account for $0.39 \%, 0.22 \%, 0.22 \%, 0.22 \%, 0.22 \%, 0.22 \%$ and $0.28 \%$ of the full wavebands, which simplified the model and improved the efficiency. Most of the selected wavelengths for nitrogen levels were found in the first region (350-1000 nm), indicating that this region contains wavelengths that are sensitive to this response. This explains why 350-1000 nm obtained better prediction result than the other two spectral regions (1001-1350/1425-1800 nm and 2000-2400 nm). Only a few selected wavelengths (1042 nm, $1124 \mathrm{~nm}$ and $1125 \mathrm{~nm}$ ) were found in the spectral ranges of $1001-1350 / 1425-1800 \mathrm{~nm}$ and no wavelengths were found to be significant within the $2000-2400 \mathrm{~nm}$ range. This explains why wavelengths within the ranges of 1001-1350/1425-1800 nm performed the second best for prediction and 2000-2400 nm performed the worst. For each set of data, the selected wavelengths are mainly around the green peak, chlorophyll absorption, red edge and near infrared regions, which is because the nitrogen content is directly related to greenness, chlorophyll content and leaf area index ${ }^{[30]}$.

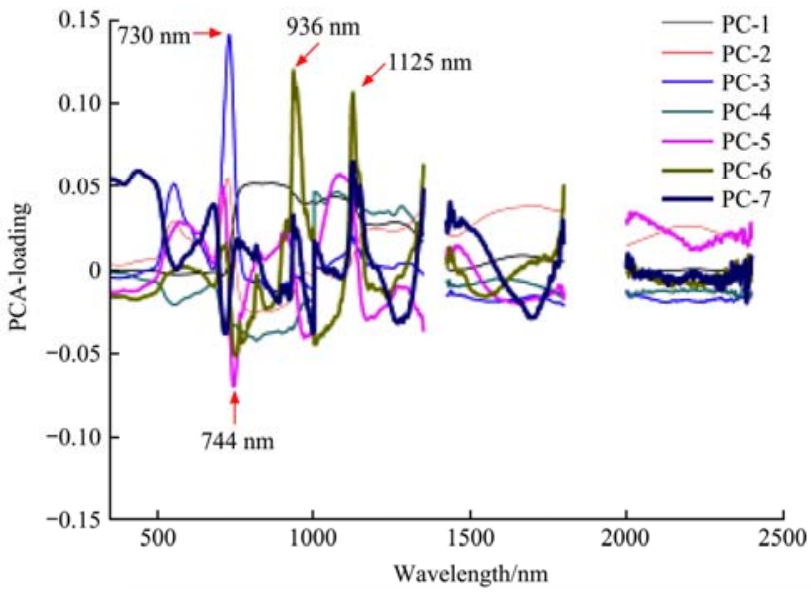

b. $7 / 13 / 2015$

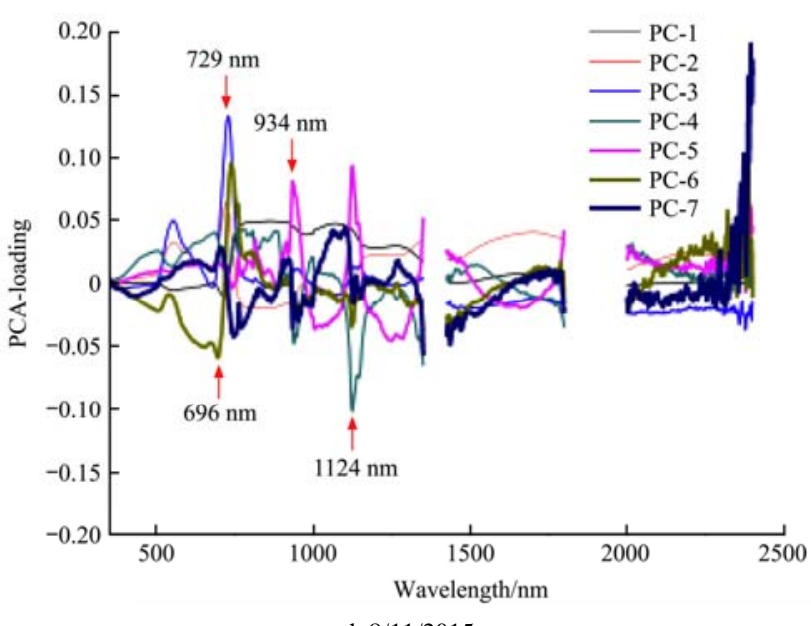



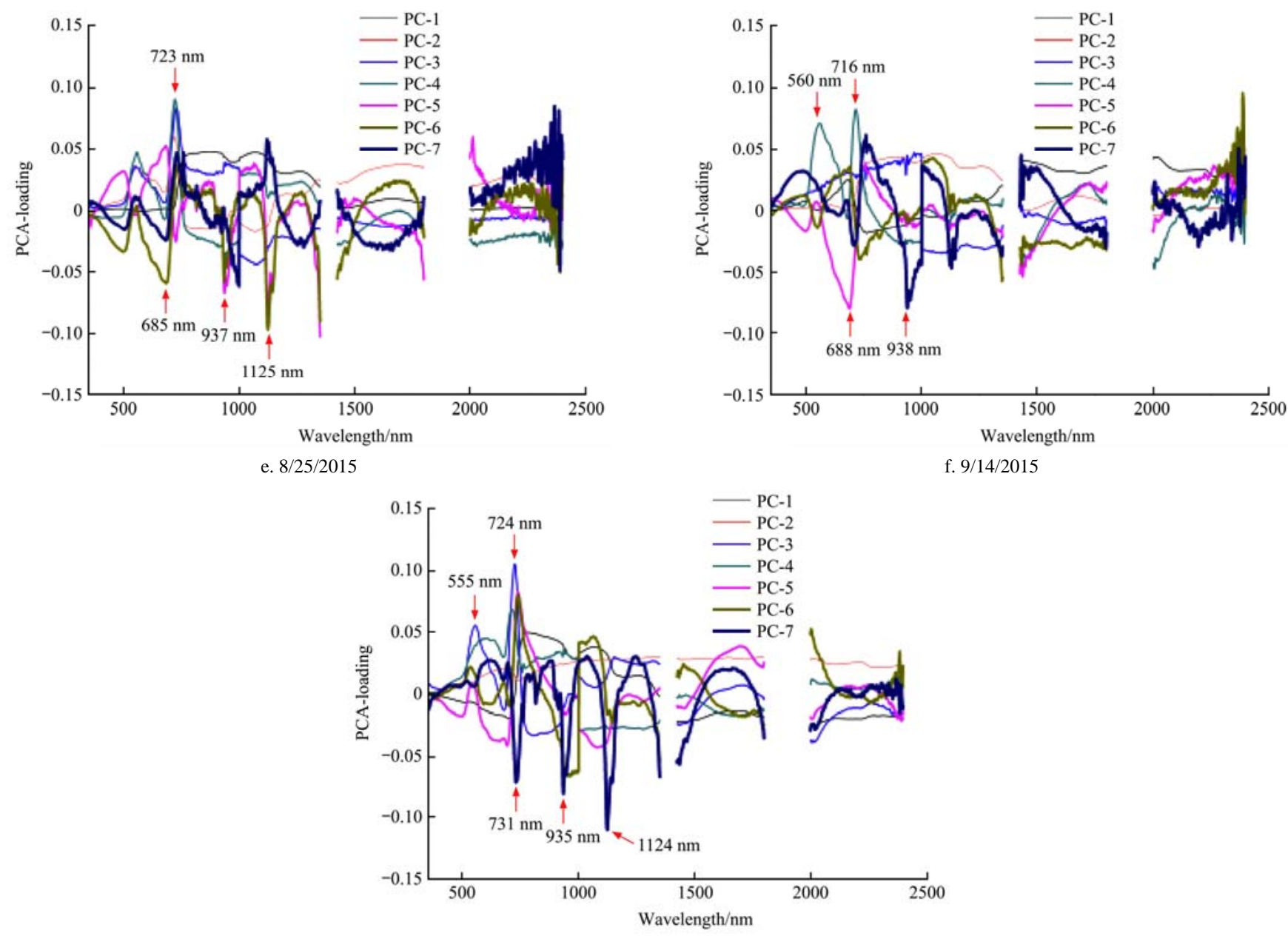

g. Overall data

Figure 3 PCA-loading plots of the first seven PCs for wavelengths selection

\subsection{MLR prediction results based on selected wavelengths}

MLR models were then carried out to evaluate the performance of the selected wavelengths, and the corresponding results can be seen in Table 4. It was also the three data sets (6/29/2015, $7 / 29 / 2015$ and 8/11/2015) that obtained good prediction results, while the data acquired on 9/14/2015 performed the worst. Compared with PLS models based on full wavelengths, most of the results in MLR models increased (except 7/13/2015). It may be because the full wavelengths contain much redundant information,

Table 4 Prediction results of MLR models based on selected wavelengths by PCA-loading

\begin{tabular}{cccc}
\hline Date & Parameters & Calibration & Prediction \\
\hline \multirow{2}{*}{$6 / 29 / 2015$} & $R^{2}$ & 0.8061 & 0.7526 \\
& $R M S E$ & 0.2006 & 0.2357 \\
\hline \multirow{2}{*}{$7 / 13 / 2015$} & $R^{2}$ & 0.7549 & 0.5591 \\
& $R M S E$ & 0.2255 & 0.7477 \\
\hline \multirow{2}{*}{$7 / 29 / 2015$} & $R^{2}$ & 0.7097 & 0.8251 \\
& $R M S E$ & 0.2454 & 0.1951 \\
\hline \multirow{2}{*}{$8 / 11 / 2015$} & $R^{2}$ & 0.6820 & 0.8102 \\
& $R M S E$ & 0.2569 & 0.2125 \\
\hline \multirow{2}{*}{$8 / 25 / 2015$} & $R^{2}$ & 0.7151 & 0.7195 \\
& $R M S E$ & 0.2431 & 0.2423 \\
\hline \multirow{2}{*}{ 9/14/2015 } & $R^{2}$ & 0.3158 & 0.5354 \\
& $R M S E$ & 0.3768 & 0.3233 \\
\hline \multirow{2}{*}{ Overall } & $R^{2}$ & 0.6830 & 0.6735 \\
& $R M S E$ & 0.2565 & 0.3457 \\
\hline
\end{tabular}

which affected the prediction ability. However, the result of overall data increased by $20.92 \%$. Moreover, the number of input variables for overall data decreased from 1778 to 5, which reduced the calculation time and improved the prediction efficiency. The comparison of full and selected wavelengths can be seen in Figure 4. Most of the results in MLR models (selected wavelengths) were found to be better than those in PLS models (full wavelengths), proving again that selected wavelengths can even produce better results than full wavelengths.

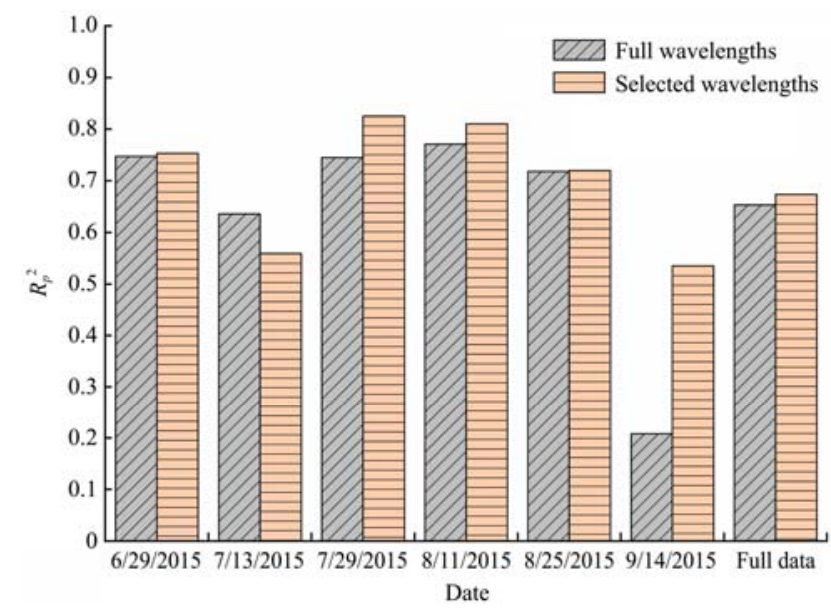

Figure 4 Comparison of full (PLS models) and selected wavelengths (MLR models)

\subsection{Linear regression equations}

In order to find the quantitative relationship between the 
spectral reflectance and nitrogen values, the regression coefficients of each MLR model were calculated, leading to linear equations shown as follows. Based on these equations, BMP values can be calculated easily only by the reflectance values at the selected wavelengths. Also, a simple nitrogen detection sensor with several wavebands can be developed using the selected wavelengths.
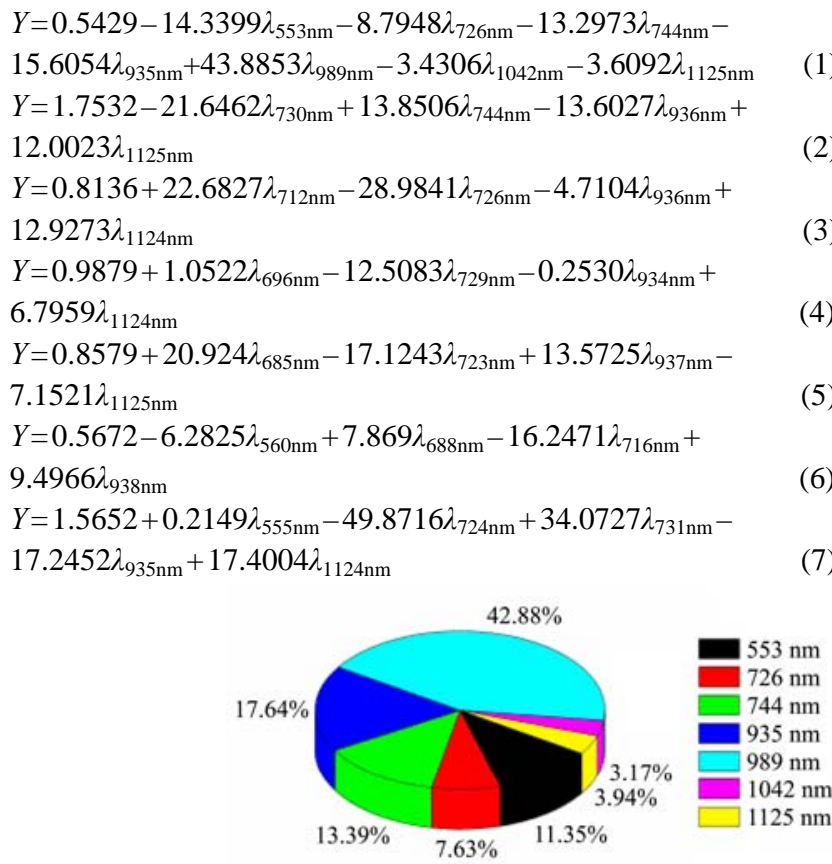

a. $6 / 29 / 2015$

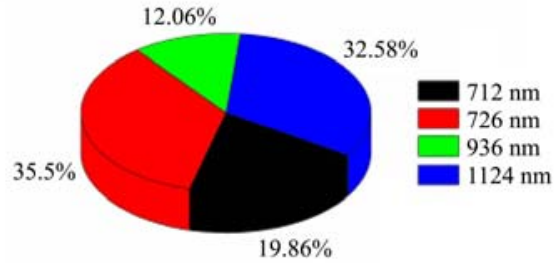

c. $7 / 29 / 2015$

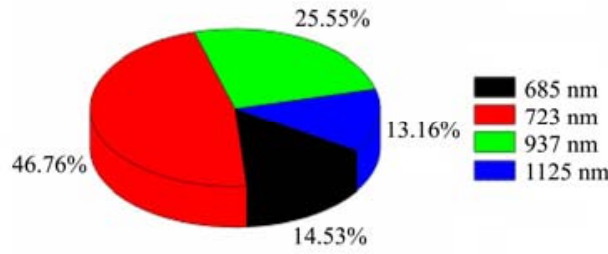

e. $8 / 25 / 2015$ where, $\lambda_{\text {inm }}$ is the spectral reflectance value of wavelength $i$; $Y$ is the BMP value.

Equations (1-7) are corresponding to the PCA-loading-MLR models for 6/29/2015, 7/13/2015, 7/29/2015, 8/11/2015, 8/25/2015, 9/14/2015 and overall data, respectively.

\subsection{T-values of each selected wavelengths}

The coefficient values in MLR models do not stand for the significance of the wavelength variables since the sizes of the coefficients are decided by the range of variation of these variables, indicating that small coefficient values do not mean the variables are unimportant and large values do not indicate the variables are significant. Thus, the performance of each selected wavelength was evaluated using $t$-values. The $t$-value is the ratio of deviation and standard error of the mean. The large absolute $t$-value mean the wavelength is more significant. The $t$-value of each variable at different dates can be seen in Figure 5. It can be found that different wavelengths performed variously in MLR models, and the wavelengths around $555 \mathrm{~nm}$ and $730 \mathrm{~nm}$ played the most significant roles in the prediction. Generally, the wavelength around $730 \mathrm{~nm}$ performed the best in most of the models.

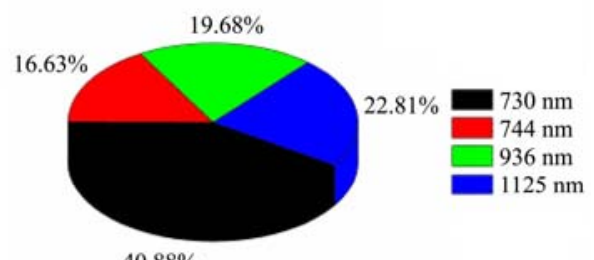

b. $7 / 13 / 2015$

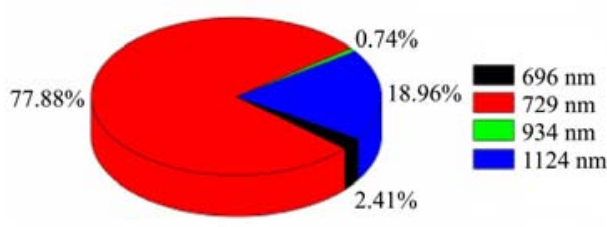

d. $8 / 11 / 2015$

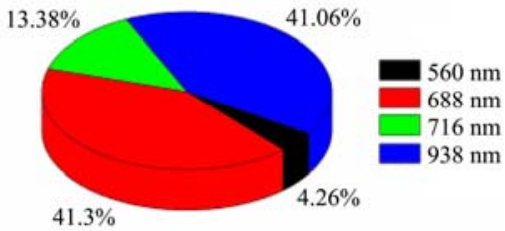

f. $9 / 14 / 2015$

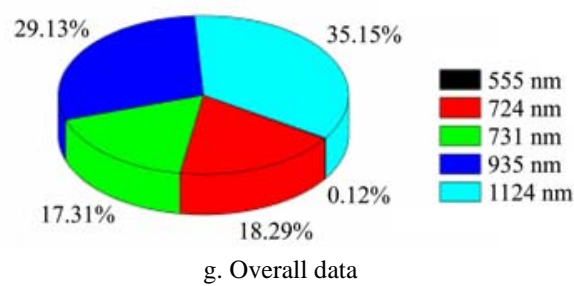

Figure 5 The $t$-values of MLR models for each selected wavelength at different dates

\subsection{Performance of vegetation indices}

PLS and MLR models were finally established using VIs, and the results can be seen in Table 5. Compared with PLS results based on spectral reflectance, the results in VIs-based PLS models increased on 7/13/2015, 7/29/2015, 8/11/2015, 8/25/2015 and 9/14/2015. For MLR models, most of the results decreased. The overall results demonstrated that the spectral reflectance is more effective than VIs. This is because spectral reflectance contains more useful information than VI.

The Pearson correlation and significance as well as $F$ value and significance were used to identify the performance of each VI. The results were shown in Table 6, in which most of the VIs had good correlation with nitrogen level values (high correlation values and low significance values), demonstrating that VIs can be used to evaluate the nitrogen stress as well. Among all VIs, VOG 2 performed the best with the highest values of correlation 
(0.425) and F (27.401) as well as the lowest value of significance (0.000).

Table 5 Prediction results of PLS and MLR models using VIs

\begin{tabular}{|c|c|c|c|c|c|}
\hline \multirow{2}{*}{ Date } & \multirow{2}{*}{ Parameters } & \multicolumn{2}{|c|}{ PLS } & \multicolumn{2}{|c|}{ MLR } \\
\hline & & Calibration & Prediction & Calibration & Prediction \\
\hline \multirow{2}{*}{ 6/29/2015 } & $R^{2}$ & 0.6713 & 0.6222 & 0.7991 & 0.8097 \\
\hline & $R M S E$ & 0.2612 & 0.2800 & 0.2042 & 0.2030 \\
\hline \multirow{2}{*}{ 7/13/2015 } & $R^{2}$ & 0.7493 & 0.6602 & 0.8093 & 0.5981 \\
\hline & $R M S E$ & 0.2281 & 0.2655 & 0.1989 & 0.2931 \\
\hline \multirow{2}{*}{ 7/29/2015 } & $R^{2}$ & 0.6806 & 0.7781 & 0.7748 & 0.6577 \\
\hline & $R M S E$ & 0.2574 & 0.2146 & 0.2162 & 0.3230 \\
\hline \multirow{2}{*}{ 8/11/2015 } & $R^{2}$ & 0.6718 & 0.7806 & 0.7651 & 0.6925 \\
\hline & $R M S E$ & 0.2610 & 0.2133 & 0.2208 & 0.2683 \\
\hline \multirow{2}{*}{$8 / 25 / 2015$} & $R^{2}$ & 0.6723 & 0.7257 & 0.7747 & 0.7684 \\
\hline & RMSE & 0.2608 & 0.2386 & 0.2162 & 0.2281 \\
\hline \multirow{2}{*}{ 9/14/2015 } & $R^{2}$ & 0.5075 & 0.2983 & 0.6255 & 0.4114 \\
\hline & RMSE & 0.3197 & 0.3816 & 0.2788 & 0.4014 \\
\hline \multirow{2}{*}{ Overall } & $R^{2}$ & 0.5953 & 0.5655 & 0.6211 & 0.5549 \\
\hline & $R M S E$ & 0.2898 & 0.3033 & 0.2804 & 0.3071 \\
\hline
\end{tabular}

Table 6 Correlation and analysis of variance (ANOVA) of VIs

\begin{tabular}{ccccc}
\hline \multirow{2}{*}{$\begin{array}{c}\text { Vegetation } \\
\text { indices }\end{array}$} & \multicolumn{2}{c}{ Correlation analysis } & \multicolumn{2}{c}{ Analysis of variance (ANOVA) } \\
\cline { 2 - 3 } \cline { 5 - 5 } & Correlation & Significance & F value & Significance \\
\hline NDVI & 0.510 & 0.323 & 0.345 & 0.793 \\
SRI & 0.184 & 0.000 & 4.417 & 0.005 \\
EVI & 0.155 & 0.003 & 3.042 & 0.029 \\
ARVI & 0.051 & 0.321 & 0.346 & 0.792 \\
SGI & -0.269 & 0.000 & 9.700 & 0.000 \\
NDVI & 0.225 & 0.000 & 6.695 & 0.000 \\
mSR $_{705}$ & 0.284 & 0.000 & 10.856 & 0.000 \\
mNDVI $_{705}$ & 0.234 & 0.000 & 7.293 & 0.000 \\
VOG 1 & 0.363 & 0.000 & 18.860 & 0.000 \\
VOG 2 & 0.425 & 0.000 & 27.401 & 0.000 \\
VOG 3 & 0.421 & 0.000 & 26.749 & 0.000 \\
NDNI & 0.034 & 0.514 & 0.142 & 0.934 \\
\hline Note: $p=0.01$ & & & &
\end{tabular}

\section{Conclusions}

The relationship between spectral reflectance and different nitrogen level values was studied in this work. The full wavelengths of each date obtained a good result with $R_{p}{ }^{2}$ higher than 0.6359 in the prediction set (except 9/14/2015). For the three different sets of wavebands, 350-1000 nm performed the best. This is because most of the sensitive wavelengths of nitrogen were in this spectral region, which was also corresponding to the selected wavelengths by PCA-loading. The selected wavelengthsbased MLR models even got better prediction results than PLS models (full wavelengths), indicating that PCA-loading was effective for wavelengths selection. The two significant wavelengths ( $555 \mathrm{~nm}$ and $730 \mathrm{~nm}$ ) have the potential to be used for designing a simple detection sensor for nitrogen management. The wavelength $730 \mathrm{~nm}$ performed the best according to t-values. Among VIs, VOG 2 performed the best. The overall results demonstrated that spectral reflectance collected by spectroradiometer could be an ideal tool for nitrogen fertilization management in field grown corn.

\section{Acknowledgements}

This work was supported by University of Minnesota Informatics Institute (UMII) on the Horizon Initiative and the Minnesota Long-Term Agricultural Research Network (LTARN) Program. Special thanks to Mr. Randy Gettle from Farm Nutrients Inc.

\section{[References]}

[1] https://quickstats.nass.usda.gov/\#840757A6-4A7E-3BC5-8904-1F3DD7E FCA7E.

[2] Daughtry C S T, Walthall C L, Kim M S, Colstoun E B, McMurtrey Iii J E. Estimating corn leaf chlorophyll concentration from leaf and canopy reflectance. Remote Sensing of Environment, 2000; 74(2): 229-239.

[3] Vigneau N, Ecarnot M, Rabatel G, Roumet P. Potential of field hyperspectral imaging as a nondestructive method to assess leaf nitrogen content in wheat. Field Crops Research, 2011; 122(1): 25-31.

[4] Jørgensen R N, Christensen L K, Bro R. Spectral reflectance at sub-leaf scale including the spatial distribution discriminating NPK stress characteristics in barley using multiway partial least squares regression. International Journal of Remote Sensing, 2007; 28(5): 943-962.

[5] Blackmer T M, Schepers J S, Varvel G E, Walter-Shea E A. Nitrogen deficiency detection using shortwave radiation from irrigated corn canopies. Agronomy Journal, 1996; 88(1): 1-5.

[6] Cassman K G, Dobermann A, Walters D T. Agroecosystems, nitrogen-use efficiency, and nitrogen management. AMBIO: A Journal of the Human Environment, 2002; 31(2): 132-140.

[7] Yu K Q, Zhao Y R, Li X L, Shao Y N, Liu F, He Y. Hyperspectral imaging for mapping of total nitrogen spatial distribution in pepper plant. Plos One, 2014; 9(12).

[8] Rathke G W, Behrens T, Diepenbrock W. Integrated nitrogen management strategies to improve seed yield, oil content and nitrogen efficiency of winter oilseed rape (Brassica napus L.): a review. Agriculture, Ecosystems \& Environment, 2006; 117(2): 80-108.

[9] Zhang X L, Liu F, He Y, Gong A P. Detecting macronutrients content and distribution in oilseed rape leaves based on hyperspectral imaging. Biosystems Engineering, 2013; 115(1): 56-65.

[10] Arregui L M, Lasa B, Lafarga A, Iraneta I, Baroja E, Quemada M. Evaluation of chlorophyll meters as tools for $\mathrm{N}$ fertilization in winter wheat under humid Mediterranean conditions. European Journal of Agronomy, 2006; 24(2): 140-148.

[11] Tarpley L, Reddy K R, Sassenrath-Cole G F. Reflectance indices with precision and accuracy in predicting cotton leaf nitrogen concentration. Crop Science, 2000; 40(6): 1814-1819.

[12] Min M, Lee W S. Determination of significant wavelengths and prediction of nitrogen content for citrus. Transactions of the ASAE, 2005; 48(2): 455-461.

[13] Albayrak S. Use of reflectance measurements for the detection of N, P, $\mathrm{K}, \mathrm{ADF}$ and NDF contents in sainfoin pasture. Sensors, 2008; 8(11): 7275-7286

[14] Minnesota Department of Agriculture. http://www.mda.state.mn.us/ nitrogenbmps

[15] Xie C Q, Li X L, Nie P C, He Y. Application of time series hyperspectral imaging (TS-HSI) for determining water content within tea leaves during drying. Transactions of the ASABE, 2013; 56(6): 1431-1440.

[16] Cen H Y, Bao Y D, He Y, Sun D W. Visible and near infrared spectroscopy for rapid detection of citric and tartaric acids in orange juice. Journal of Food Engineering, 2007; 82(2): 253-260.

[17] He Y, Huang M, García A, Hernández A, Song H Y. Prediction of soil macronutrients content using near-infrared spectroscopy. Computers and Electronics in Agriculture, 2007; 58(2): 144-153.

[18] Zou X B, Shi J Y, Hao L M, Zhao J W, Mao H P, Chen Z W, et al. In vivo noninvasive detection of chlorophyll distribution in cucumber (Cucumis sativus) leaves by indices based on hyperspectral imaging. Analytica Chimica Acta, 2011; 706(1): 105-112.

[19] Kamruzzaman M, ElMasry G, Sun D W, Allen P. Prediction of some quality attributes of lamb meat using near-infrared hyperspectral imaging and multivariate analysis. Analytica Chimica Acta, 2012; 714: 57-67.

[20] Bieroza M, Baker A, Bridgeman J. New data mining and calibration approaches to the assessment of water treatment efficiency. Advances in Engineering Software, 2012; 44(1): 126-135.

[21] Wu D, Chen X J, Zhu X G, Guan X C, Wu G C. Uninformative variable 
elimination for improvement of successive projections algorithm on spectral multivariable selection with different calibration algorithms for the rapid and non-destructive determination of protein content in dried laver. Analytical Methods, 2011; 3(8): 1790-1796.

[22] Kamruzzaman M, ElMasry G, Sun D W, Allen P. Application of NIR hyperspectral imaging for discrimination of lamb muscles. Journal of Food Engineering, 2011; 104(3): 332-340.

[23] Xie C Q, Li X L, Shao Y N, He Y. Color measurement of tea leaves at different drying periods using hyperspectral imaging technique. Plos One, 2014; 9(12)

[24] ElMasry G, Sun D W, Allen P. Near-infrared hyperspectral imaging for predicting colour, $\mathrm{pH}$ and tenderness of fresh beef. Journal of Food Engineering, 2012; 110(1): 127-140.

[25] Bannari A, Morin D, Bonn F, Huete A R. A review of vegetation indices. Remote sensing reviews, 1995; 13(1-2): 95-120.
[26] ENVI 4.7 software (ITT Visual Information Solutions Inc., Boulder, CO, USA) help.

[27] Min M, Lee W S, Kim Y H, Bucklin R A. Nondestructive detection of nitrogen in Chinese cabbage leaves using Vis-NIR spectroscopy. HortScience, 2006; 41(1): 162-166.

[28] Yang C, Lee W S, Williamson J G. Classification of blueberry fruit and leaves based on spectral signatures. Biosystems Engineering, 2012; 113(4): 351-362.

[29] Huang W J, Lamb D W, Niu Z, Zhang Y J, Liu L Y, Wang J H. Identification of yellow rust in wheat using in-situ spectral reflectance measurements and airborne hyperspectral imaging. Precision Agriculture, 2007; 8(4-5): 187-197.

[30] Jain N, Ray S S, Singh J P, Panigrahy S. Use of hyperspectral data to assess the effects of different nitrogen applications on a potato crop. Precision Agriculture, 2007; 8(4-5): 225-239. 